\title{
Successful endoscopic full-thickness resection of intramucosal cancer with Aurora rings arising in a diverticulum
}

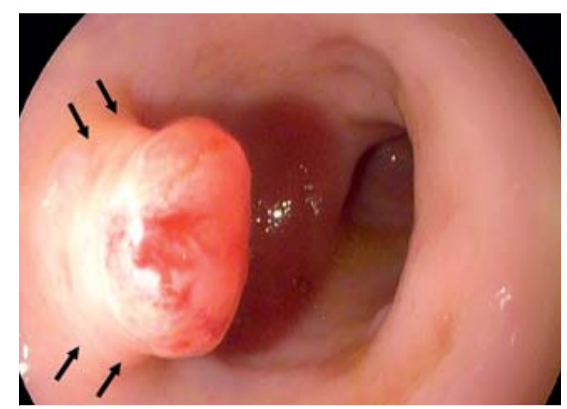

- Fig. 1 Endoscopic view showing concentric rings - Aurora rings (arrows) around the polypoid lesion of the sigmoid colon, suggesting that the lesion originated in a diverticulum.

The diagnosis and treatment of polypoid lesions located in diverticula is challenging. Aurora rings - concentric rings around a polypoid lesion [1] - may indicate an origin in a diverticulum, and accordingly dedicated endoscopic treatment should be planned. Intradiverticular lesions can be treated by several endoscopic approaches [2-5]. We report the case of a polypoid lesion originating in a diverticulum with the Aurora rings sign and intramucosal cancer which was successfully resected using an endoscopic full-thickness resection device (FTRD, Ovesco, Tübingen, Germany).

A 55-year-old woman underwent colonoscopy after a positive fecal occult blood test. A 10-mm sessile polyp (Paris 0 -Is) with Aurora rings was observed in the sigmoid colon ( $\mathbf{F i g . 1}$, > Fig. 2 ). Because the lesion originated in a diverticulum and showed a tortuous surface pattern morphology, a single biopsy at the edge of the lesion was performed first. The biopsy revealed advanced adenoma with intramucosal cancer. Full-thickness resection using the FTRD was planned. The lesion was first marked, then it was carefully pulled into the FTRD cap using the grasping forceps. Only careful suction was performed. After ensuring that the tumor was completely inside the cap, the

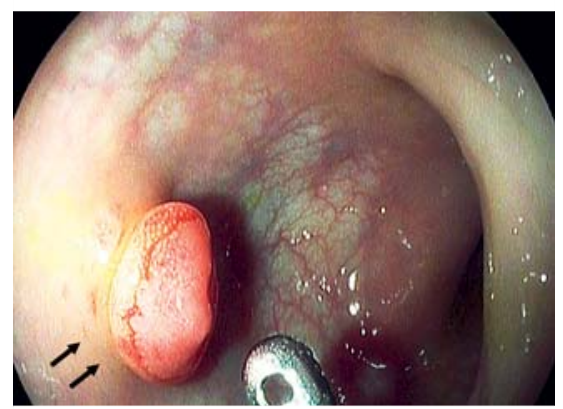

- Fig. 2 Endoscopic view showing the Aurora rings (arrows) around the polypoid lesion (i-scan image).

FTRD clip was released and the lesion was snared and resected en bloc ( $\mathbf{F i g} . \mathbf{3}$ ). No adverse events, early or delayed, were observed.

Histology revealed the absence of a muscular layer, confirming that the lesion was located on a false diverticulum ( $\triangleright$ Fig.4). Complete resection of a tubular adenoma with intramucosal cancer was achieved with free lateral and vertical margins (R0) ( Fig. 5).

Surveillance colonoscopy performed 6 months later displayed the resected area with the over-the-scope clip (OTSC) on site. Biopsies showed granulation tissue without dysplasia.

This case shows the importance of careful endoscopic observation before standard polypectomy. The identification of the subtle endoscopic sign of the Aurora rings determined the performance of safe and accurate endoscopic curative treatment using the FTRD in this patient.

Endoscopy_UCTN_Code_TTT_1AQ_2AD

\section{Acknowledgments}

We wish to thank Dr. Manuel Rodriguez-Navarro for his support in encouraging us to perform the procedure and Juan M. Herrerias-Esteban for his help in preparing the images.

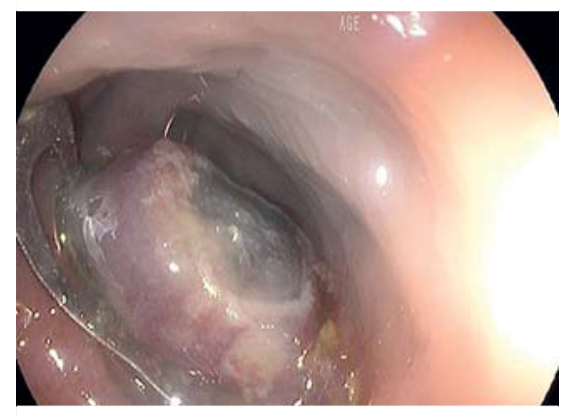

- Fig. 3 Endoscopic appearance of the resection site showing the deployed OTSC still in place.

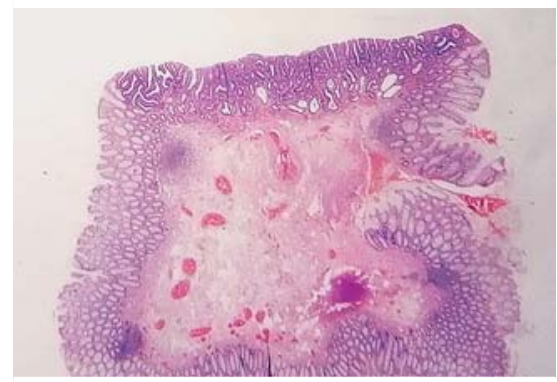

- Fig. 4 Tubular adenoma with intramucosal cancer originating in a colonic diverticulum. The lack of a muscular layer confirmed that the lesion was located in a false diverticulum. H\&E, $\times 5$.

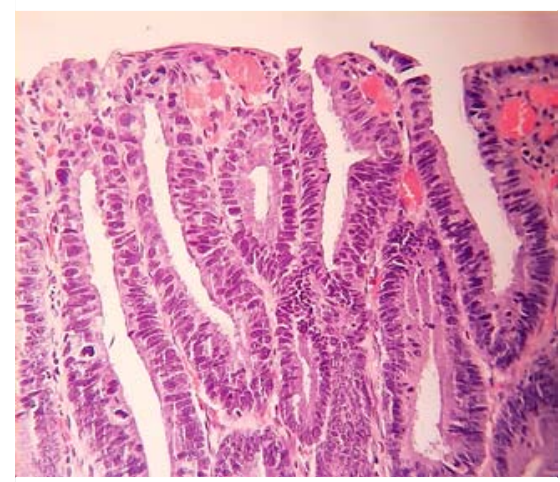

> Fig. 5 Tubular adenoma showing intramucosal cancer: nuclei are enlarged, depolarized, hyperchromatic, and pseudostratified. H\&E, $\times 40$. 


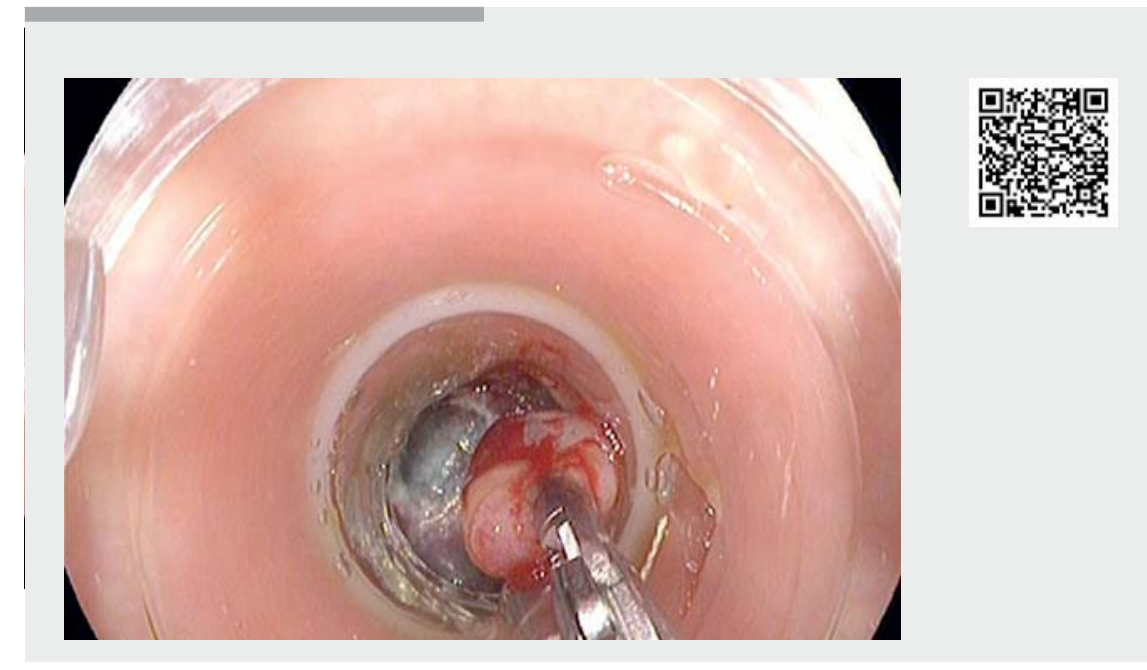

$\checkmark$ Video 1 Management by endoscopic full-thickness resection of an intramucosal cancer with Aurora rings involving a diverticulum.

\section{Competing interests}

None

The authors

Victoria A. Jimenez-Garcia ${ }^{1}$, Rafael RomeroCastro', Masayoshi Yamada², Juan SeguraSanchez ${ }^{3}$, Javier Alcazar-Guijo' ${ }^{1}$, Helmut Neumann ${ }^{4}$

1 Endoscopy Division, Hospital Vithas Nisa Sevilla, Seville, Spain

2 Endoscopy Division, National Cancer Center Hospital, Tokyo, Japan

3 Pathology Division, Hospital Vithas Nisa Sevilla, Seville, Spain

4 Department of Medicine I, University Hospital Mainz, Mainz, Germany
[3] Valli PV, Kaufmann M, Vrugt B et al. Endoscopic resection of a diverticulum-arisen colonic adenoma using a full-thickness resection device. Gastroenterology 2014; 147: 969-971

[4] Yang J, Kalloo AN, Gonzalez-Velez E et al. Modified over-the-scope clip with telescope endoscopic full-thickness resection for colonic adenoma involving diverticulum. VideoGIE 2018; 3: 316-318

[5] Jimenez-Garcia VA, Yamada M, Ikematsu H et al. Endoscopic submucosal dissection in management of colorectal tumors near or involving a diverticulum: a retrospective case series. Endosc Int Open 2019; 7: E664E671

\section{Bibliography}

DOI https://doi.org/10.1055/a-1065-1517

Published online: 13.12.2019

Endoscopy 2020; 52: E200-E201

(c) Georg Thieme Verlag KG

Stuttgart $\cdot$ New York

ISSN 0013-726X

\section{Victoria Alejandra Jimenez-Garcia, MD PhD}

Endoscopy Division, Hospital Vithas Nisa Sevilla, Av. Placido Fernandez Viagas s/n. 41950, Castilleja de la Cuesta, Seville, Spain drajimenezg@hotmail.com

\section{References}

[1] Share MD, Avila A, Dry SM et al. Aurora rings: a novel endoscopic finding to distinguish inverted colonic diverticula from colon polyps. Gastrointest Endosc 2013; 77: 308312

[2] Carmo J, Marques S, Chapim I et al. Elastic band ligation for the removal of a colonic tubular adenoma in a diverticulum. Endoscopy 2015; 47 (Suppl. 01): E490-E491

\section{ENDOSCOPY E-VIDEOS}

https://eref.thieme.de/e-videos

回起 Endoscopy E-Videos is a free

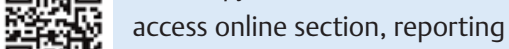
靣转: on interesting cases and new techniques in gastroenterological endoscopy. All papers include a high quality video and all contributions are freely accessible online.

This section has its own submission website at https://mc.manuscriptcentral.com/e-videos 